\title{
Associação Brasileira de Enfermagem - Seção Sergipe: 52 anos de vontade, garra e coração
}

\author{
Brazilian Nursing Association, Sergipe Section: 52 years of will, claw, and heart \\ Asociación Brasileña de Enfermería, Sección Sergipe: 52 años de voluntad, perseverancia y corazón
}

\author{
Maria Cláudia Tavares de Mattos', Maria Pontes de Aguiar Campos' \\ 'Universidade Federal de Sergipe. Departamento de Enfermagem. Aracaju, SE
}

Submissão: 02/06/2009

Aprovação: 09/07/2010

\section{RESUMO}

Trata-se de uma contribuição à história da Enfermagem sergipana e, por conseguinte a Enfermagem brasileira. Objetiva resgatar a história da Associação Brasileira de Enfermagem, Seção Sergipe (ABEn-SE) e documentar o desempenho dessa entidade nos cenários científico, cultural e político. Pesquisa Qualitativa cujos dados foram coletados através de história oral e história oficial registrada em livros, atas, jornais e documentos. Os dados foram submetidos à análise de conteúdo. É apresentada a história através de algumas das personagens desse enredo mostrando Que o presente pode ser um produto do passado já que encerra uma escrita da história construída e moldada pela vontade de seus atores. Conclui-se Que repensar a história da ABEn-SE é repensar nossas próprias vidas e a capacidade de interagir com a categoria.

Descritores: História da enfermagem; Associações; Enfermagem.

\section{ABSTRACT}

This is a contribution for the history of nursing from Sergipe and, as a consequence, for the Brazilian Nursing. It aims at rescuing the Brazilian Nursing Association, Sergipe's Section history and to document the accomplishment of this entity into the scientifical, cultural and political scenery. A Qualitative research, whose data were collected by means of oral and official history registered on books, journals, and other documents. Data were submitted to content analysis. That history is presented by some characters from this plot, indicating that present may be an answer from the past because it contains the writing of the history founded by its actor's will. It was concluded that rethinking Brazilian Nursing Association, Sergipe's Section history is rethinking our own capability of interaction with the category.

Keywords: History of nursing. Associations; Nursing.

\section{RESUMEN}

Se trata de una contribución a la historia de la enfermería de Sergipe y por consiguiente a la Enfermería Brasileña. Objetiva rescatar la historia de la Asociación Brasileña de Enfermería, Sección Sergipe y documentar el desempeño de esa entidad en los escenarios científicos, cultural y político. Pesquisa cualitativa cuyos datos fueron recogidos a través dela historia oral y oficial registrada en libros, actas, periódicos y documentos. Los datos fueron sometidos para análisis de contenido. Presentase la historia por medio de algunos de los personajes de ese medio indicando que el presente puede ser el fruto del pasado, ya Que, encierra una escrita de la historia establecida por el encelo de sus autores. Se concluye que repensar la historia de la Asociación Brasileña de Enfermería, Sección Sergipe es repensar nuestras vidas y repensar la capacidad de interactuar con la clase.

Descriptores: Historia de la enfermería; Asociasiones; Enfermería. 


\section{INTRODUÇÃO}

Este artigo é fruto de um livro publicado sobre a História da Associação Brasileira de Enfermagem, Seção Sergipe (ABEn-SE). O presente trabalho ousa ser uma contribuição à história da Enfermagem sergipana e, por conseguinte a Enfermagem brasileira. Ao eleger como objeto de estudo os 52 anos de história e de lutas da ABEn-SE, reconstruímos a trajetória de uma instituição Que, a partir dos anos 1950, vem marcando a vida cultural, científica e política da Enfermagem Sergipana, trazendo encontros, seminários, semanas científicas, onde não havia seQuer a esperança de um curso superior de Enfermagem em nosso Estado( ${ }^{(1)}$.

Não nos furtamos a analisar as contradições da instituição, além de colocar em relevo o entusiasmo das abenistas impregnadas da idéia de Que a ABEn seria a grande alavanca de mudanças na Enfermagem sergipana.

Buscamos ouvir as vozes do silêncio que se produziu em torno da ABEn, transpondo os limites da história-narração e problematizando a história através de seu caráter científico da história em construção. A ampliação da noção de fonte se deu com a história de vida para montarmos nessa colcha de retalhos, possibilidades de explicitação do nosso objeto, construindo temporalidades múltiplas e reconhecendo as ligações entre o passado e o presente ${ }^{(1)}$.

O considerável volume de informações constituiu-se problema no momento da sistematização, uma vez Que sua supressão representava abandonos às longas horas de coleta nos areuivos da ABEn$\mathrm{SE}$, bem como nas falas memoráveis dos entrevistados. Ainda assim, a necessidade imperiosa de estruturar o trabalho, nos levou a definir categorias a partir das Quais o livro foi organizado em Quatro capítulos ${ }^{(1)}$.

No primeiro momento "Da InQuietação Surge o Compromisso", contextualizamos o surgimento da ABEn no cenário sergipano. $\mathrm{O}$ direcionamento dado para compreender a sua estrutura, as formas Que propiciaram sua expansão, as interferências e os motivos Que ocasionaram a inserção desses interlocutores na $A B E n$ foram tratados em um segundo momento nominado, "A Afirmação da Cientificidade e da Organização da Classe".

Em momento terceiro, "Confirmando a função Social, Cultural e Científica”, é retratado como ponto de inserção no terceiro milênio, enfatizado pelo holísmo que a Enfermagem demanda.

Nas considerações finais, "ABEn-SE: 52 anos, Várias Vidas Compondo uma História", retomamos algumas constatações efetuadas no corpo do trabalho e encerramos destacando as principais realizações e as avaliações Que nossos interlocutores fizeram da entidade e da própria atuação enQuanto estiveram a ela vinculados $^{(1) .}$ Os objetivos do estudo foram: Resgatar a história da Associação Brasileira de Enfermagem -seção Sergipe e documentar em livro todo o desempenho dessa entidade nos cenários científico, cultural e político.

\section{MÉTODO}

Tratou-se de uma pesquisa Qualitativa cujos dados foram coletados através da história oral, e da história oficial registrada em livros, atas, jornais e documentos. O local de estudo foi a cidade de Aracaju, capital do Estado de Sergipe.

Inicialmente buscou-se a história oficial através dos escritos re- gistrados em documentos oficiais junto à sede da ABEn-SE. Para a execução desta etapa tivemos a colaboração de alunos do Curso de Enfermagem da Universidade Federal de Sergipe, Que foram devidos e previamente treinados pelas autoras a fim de Que fossem melhor captadas as informações pertinentes ao objeto em estudo.

Na segunda etapa após a identificação das lacunas e vazios temporais, procedemos à realização da história oral com os atores sociais Que vivenciaram esta história e Que muito contribuíram para a amplitude da mesma. Utilizou-se a entrevista não estruturada, realizada no total com dez atores aos Quais foram apresentados os pontos principais a discorrer sobre o objeto específico do estudo, ficando estes livres para falar sobre outros pontos.

A escolha dos entrevistados foi intencional, uma vez Que só os personagens Que participaram efetivamente da construção dessa história tem as contribuições indispensáveis, sendo feita a identificação dos nomes por meio dos documentos oficiais da ABEn/SE. Dentro da história oral, escolheu-se a história oral de vida ${ }^{(2)}$ Que diz respeito ao conjunto de experiência de vida de uma pessoa, colocando-se temas de forma ampla, por estar em Questão a representação dos indivíduos sobre fatos de sua própria vida Que dizem respeito ao tema estudado e na medida em Que se foi realizando cada entrevista, pediu-se ao entrevistado a indicação de outros nomes Que participaram dessa história e assim formando a rede de informantes.

$\mathrm{Na}$ terceira fase, os dados foram submetidos à análise de conteúdo Qualitativa, ao eual fizemos inicialmente uma pré-análise constituída de uma leitura flutuante e em seguida uma leitura dirigida fazendo o corpo de análise para a elaboração propriamente dita do livro(3)

\section{Da inQuietação surge o compromisso}

A história da ABEn-SE está intimamente ligada à história da Enfermagem e da Saúde em Sergipe. Alguns fatos e circunstâncias culminaram com a criação desta seção, Que passou, então a coordenar, os destinos, e até a vida social dos profissionais da Enfermagem no Estado(1).

De 193 I a 1954 ocorrem fatos relevantes para a Enfermagem, entre eles descata-se em 1937, a vinda para Sergipe da primeira enfermeira profissional D. Opelina Rollemberg, Que concluiu o curso de Enfermagem da Escola Ana Néri-RJ, Que incorpora-se ao Quadro de enfermeiros Hospital de Cirurgia. Só em 1952 incorpora-se ao Quadro de enfermeiros do mesmo hospital, a enfermeira Carmem Aguiar Novaes, e ainda nesse mesmo ano a Escola de Auxiliar de Enfermagem "Dr Augusto Leite", inicia suas atividades ${ }^{(4)}$.

O conjunto dos fatos relatados, com a consegüente vinda de outras enfermeiras para o Estado, levou a Que se manifestasse a necessidade da criação de uma Associação Que servisse de base técnica, social e organizativa para os profissionais.

No período de 1954-1957(3) exatamente em 12 de abril de 1954 o grupo de enfermeiras, presidida por Isabel C. Macintyre, diretora da Escola de Auxiliares de Enfermagem, do Hospital de Cirurgia, cria a diretoria provisória da ABEn-SE com a finalidade de organizá-la e eleger sua diretoria efetiva. Um mês depois tomou posse a primeira diretoria, tendo como presidente Opelina Rollemberg. Deste ponto em diante, a história da ABEn-SE se confunde com a história da Enfermagem em Sergipe, pois todas as iniciativas partiam ou se faziam acompanhar da Associação. 
O ano de 1958, foi marcado pela aprovação por unanimidade do Código Nacional de Ética de Enfermagem, a ABEn-SE, envia aos membros da Assembléia Estadual, correspondência solicitando Que fosse encadeada a carreira de Enfermeira no nível 18 do Quadro Federal.

Em 1959 a atual diretoria, divulgou os princípios Que direcionam a Enfermagem, incentivando a publicação do conhecimento técnico e científico em um jornal de grande circulação na época chamado "A Cruzada". Tal projeto teve inicio em 7 de abril de 1959 Quando a enfermeira Maria José dos Santos publicou o trabalho intitulado "A enfermeira e seus conhecimentos técnicos, científicos e morais"(1).

A gestão de 1960 formou comissões Que realizaram visitas aos poderes públicos como a Secretária de Saúde, Governo do Estado e Delegacia do Trabalho, com a proposta de evitar a criação de cargos ilegais de Enfermeiros, ou seja, exigir Que no Quadro de trabalhadores do Estado fosse colocado o profissional de Enfermagem, e Que a nomeação do mesmo fosse realizada de acordo com as leis Que regiam o exercício da profissão.

De 1961 a 1962 as lutas das representantes da ABEn-SE resultaram na regulamentação do artigo 22 da Lei 1.003 da legislação Sergipana, de 10 de janeiro de 1961 Que proibiu o uso indevido do título de Enfermeiro no Estado de Sergipe e reconhecia esta entidade como de utilidade pública ${ }^{(1)}$.

Em maio de 1961, a ABEn-SE contou com a presença de uma convidada ilustre, a então presidente da ABEn Nacional, enfermeira Marina Andrade Rezende. Nessa oportunidade Marina destacou assuntos relevantes como: criação da Associação Brasileira de Auxiliares de Enfermagem filiada a ABEn; tendências da ABEn-SE Quanto a criação da ordem dos enfermeiros e do Sindicato de Classe; exposição dos trabalhos realizados por ocasião da Assembléia Geral Extraordinária da ABEn-Nacional, a Qual decidiu por dois níveis na Enfermagem: o superior e o auxiliar de enfermagem.

De 1963 a 1964 como forma de angariar recursos para a ABEn - Nacional, essa gestão, realizou o curso de "Enfermagem do Lar", rifas, cursos, desfiles de moda, sendo o lucro revertido para a campanha do tijolo, entregue por ocasião do $25^{\circ}$ Congresso Brasileiro de Enfermagem. Durante o curso a Associação aproveitou o momento para divulgar a ABEn-SE, sendo lido e apresentado o folheto "Você conhece a ABEn?".

No dia 5 de abril de 1966 a Associação perde uma figura importante da Enfermagem, uma vez que falece a primeira enfermeira do Estado de Sergipe, Opelina Rollemberg, Que era portadora da doença de Chagas. Antes do seu falecimento a presidente da ABEn-SE, Osa M. ${ }^{\mathrm{a}}$ Machado de Araújo, solicitou às colegas que a visitassem e se revezassem no cuidado a D. Opelina, conforme costume da época ${ }^{(5)}$.

\section{Afirmação da cientificidade e da organização da classe}

Em 1970, as enfermeiras Maria Iracema Freire Novaes, Silvia Linhares, Osa Maria Machado de Araújo, Maria Sílvia D. Oliveira Costa e Marlene Henrieues Ladeiras trabalharam junto a população, mostrando a necessidade do Enfermeiro "alto padrão" no Estado e da criação do Curso Superior de Enfermagem, resultando em 17 de setembro de 1975 portanto, cinco anos depois na criação do referido Curso pela Universidade Federal de Sergipe. Ainda nessa gestão foi realizado o I Encontro de Profissionais de
Enfermagem de Sergipe.

De 1977 a 1984 ressalta-se a realização do III Encontro de Enfermeiros do Nordeste, sediado e organizado pela ABEn-SE. Esse evento foi concretizado e articulado para combater a diretoria da ABEn -Nacional, uma vez Que a mesma insistia em anular as eleições dessa seção(l).

Em 22 de março de 1985, foi aprovada por unanimidade uma comissão constituída por seis enfermeiros para elaborarem os estatutos da Associação Profissional dos Enfermeiros do Estado de Sergipe. A comissão foi constituída por Martha Oliveira Barreto, Rita de Cássia Perete, Janete Firmo de Góes, Loélia Maria Campos Maia Andrade, Rosilar Diana Oliveira Crispim de Souza e Elizano Santos de Assis.

De 1986 a 1989 durante esta gestão a ABEn-SE se fez presente em assembléias e greves de profissionais de saúde do Estado e participou de discussões amplas sobre constituinte e reforma sanitária. Além disso, procurou integrar-se ao COREN-SE e a Associação Pré-Sindical( ${ }^{(1)}$.

\section{Confirmando a função social, cultural e científica.}

A gestão do período de 1989 a 1992 comunicou a compra de um terreno no Jardim Baiano (Aracaju-SE), para Que fosse construída a sede da ABEn-SE, e para tanto deu-se início a uma campanha para construção da mesma. De 1993 a 1995, a ABEN-SE participou de vários eventos de cunho cientifico no estado de Sergipe, e teve participação efetiva em eventos científicos promovidos pelas ABEns seccionais e pela ABEn-Nacional.

Algumas dificuldades foram encontradas durante a gestão Que compreendeu o período de 1995 a 1998, as reuniões eram realizadas em auditório cedido pelo Hospital Cirurgia e os documentos ficavam na casa de membros da diretoria. Além da ínfima participação dos enfermeiros e acadêmicos em reuniões e assembléias, repercutindo em número reduzido de sócios. Houve um esfacelamento da diretoria, inclusive a presidente da ABEn-SE, pediu seu afastamento $^{(1)}$.

A gestão de 1998 a 2001 , firmou um convênio entre ABEn-SE e a Secretaria Municipal de Saúde de Aracaju, para contratação de enfermeiros, cujos contratos foram baseados na prestação de serviço no 28/0 I , firmado pelo Secretário de Saúde Rogério Carvalho e a então presidente da ABEn-SE, Cássia Maria Macedo Silva Faro.

Esse convênio, anunciou novos tempos para a ABEn-SE, inclusive culminando com a compra de duas salas para instalação da nova sede da ABEn-SE. Além disso, a nova gestão, começa a participar de todos os CONABENS, haja vista uma melhoria no caixa da ABEn-SE. Ressalta-se que no CONABEN de 2000, foi assumido o compromisso no sentido de reivindicar a apuração dos crimes encomendados Que vitimaram os colegas Marcos Otávio Valadão (Presidente da ABEn-RJ) e Edma Rodrigues Valadão (Presidente do Sindicato dos Enfermeiros do Rio de Janeiro e Diretora da Federação Nacional dos Enfermeiros), mortos há 360 dias(1).

A gestão de 2001 a 2004 teve com meta principal refletir sobre o significado do momento histórico de mobilização dos trabaIhadores da área de Enfermagem, face às transformações no mundo do trabalho, à globalização e a necessidade de organização da categoria. Com esta visão uma das medidas tomada pela ABEn-SE foi a de unir-se a outras categorias para redigir uma Moção de 
Repúdio contra a categoria médica Que publicou no Jornal da Cidade (jornal de grande circulação no estado de Sergipe), a Quebra da isonomia salarial dos médicos no Programa de Saúde da Família.

A gestão de 2004 a 2007 passou por momentos difíceis, por conta do convênio anteriormente firmado entre a ABEn-SE e a Secretaria Municipal de Saúde de Aracaju, culminado com 85 processos trabalhistas e a perda da sede. Esses problemas fizeram com Que o ânimo aumentasse e essa gestão partiu para uma campanha, para aumentar o número de sócios e difundir entre os estudantes e profissionais as ações da ABEn-SE. Este objetivo foi concretizado através da realização de campanhas de filiação junto às universidades. Esse foi um período Que ainda não se encerrou(1).

\section{CONSIDERAÇÕES FINAIS}

\section{ABEn-SE: 52 anos, várias vidas compondo uma história}

Buscou-se desde os primórdios deste estudo, refletir e suscitar debates acerca da trajetória e da contribuição desta associação (ABEn-SE) para a historiografia da Enfermagem sergipana. Com tal propósito, procurou-se descrever o papel desempenhado por essa entidade no cenário científico, cultural e político da Enfermagem ${ }^{(1)}$.

Encontrou-se nos arQuivos da própria associação, respostas aos Questionamentos Que fazíamos acerca dessa entidade. A necessidade de ampliar o entendimento da Questão conduziu-nos aos personagens Que de diferentes formas e em momentos distintos delinearam sua trajetória na entidade. Tais encontros, ricos em informações, foram também reveladores de sentimentos e crenças Que permearam as ações de cada um. Nesse percurso, situamos a pre- sença da entidade fugindo da armadilha do preconceito e das verdades estabelecidas, tão afeitas a encontrar culpados e vítimas pelas mazelas da sociedade ${ }^{(1)}$.

Ao despontar no cenário sergipano em 1954, é possível afirmar Que os seus dirigentes não tinham a devida dimensão de onde esse movimento poderia chegar. As possibilidades Que foram se delineando ao longo de sua história e as relações estabelecidas condicionaram seu crescimento. Contudo, para o Sergipe dos anos 50, marcado pelo atraso econômico e já sofrendo os reflexos da política desenvolvimentista Que se anunciava para o Nordeste e para o Estado, iniciativas como a da ABEN encontrou franca receptividade $^{(1)}$.

O relativo crescimento Que as cidades foram alcançando demandaram a prestação de alguns serviços básicos, e com eles profissionais de diferentes áreas foram chegando aos municípios sergipanos. De diferentes formas, os enfermeiros oriundos do Sudeste e de outros Estados do Nordeste e as sergipanas Que foram estudar enfermagem e voltaram, tomaram conhecimento das idéias abenistas, encamparam-nas e deram-lhe significado.

Podendo contar em seus quadros com damas da sociedade, diretoras de hospitais, professoras da Universidade Federal de Sergipe, assessoras de secretários de saúde, profissionais de referência na Saúde Pública do Estado com sólida base acadêmica tiveram o mérito de imprimir na ABEn-SE um padrão de competência organizativa respeitável, eQuiparável a outras entidades mais antigas e com mais associados em nosso Estado. Repensar a história da ABEn-SE é repensar nossas próprias vidas e a capacidade de interagir com a categoria: este artigo é nossa expressão de compromisso ${ }^{(1)}$.

\section{REFERÊNCIAS}

1. Mattos MCT, Campos MPA. ABEn-SE: 52 anos de Vontade, Coração e Garra. Aracaju: Texto Pronto Gráfica e Editora Ltda; 2006.

2. Meihy ICSB. Definindo história oral e memória. Cad CERU 1996; 5(2): 52-60.

3. Bardin C. Análise de conteúdo. Lisboa: Edições 70; 2004.

4. Vieira MJ, Faro CMMS. ABEn Sergipe: 47 anos de Luta e Resitência. Rev Bras Enferm 2001; 54(2): 382-8.

5. Vieira MJ, Cardoso NCS, Andrade MAA, Gonçalves MSS, Ribeiro AG. O Início da enfermagem profissional em Sergipe: Opelina Rollemberg. Aracaju: 2001. 